\title{
Molecular and cellular mechanisms of castration resistant prostate cancer (Review)
}

\author{
YIQIAO HUANG, XIANHAN JIANG, XUE LIANG and GANGGANG JIANG \\ Department of Urology, The Fifth Affiliated Hospital of Guangzhou Medical \\ University, Guangzhou, Guangdong 510700, P.R. China
}

Received April 1,2017; Accepted January 26, 2018

DOI: $10.3892 / 01.2018 .8123$

\begin{abstract}
With increases in the mortality rate and number of patients with prostate cancer $(\mathrm{PCa}), \mathrm{PCa}$, particularly the advanced and metastatic disease, has been the focus of a number of studies globally. Over the past seven decades, androgen deprivation therapy has been the primary therapeutic option for patients with advanced $\mathrm{PCa}$; however, the majority of patients developed a poor prognosis stage of castration resistant prostate cancer (CRPC), which eventually led to mortality. Due to CRPC being incurable, laboratory investigations and clinical studies focusing on CRPC have been conducted worldwide. Clarification of the molecular pathways that may lead to CRPC is important for discovering novel therapeutic strategies to delay or reverse the progression of disease. A sustained androgen receptor (AR) signal is still regarded as the main cause of CRPC. Increasing number of studies have proposed different potential mechanisms that cause CRPC, and this has led to the development of novel agents targeting the AR-dependent pathway or AR-independent signaling. In the present review, the major underlying mechanisms causing CRPC, including several major categories of AR-dependent mechanisms, AR bypass signaling, AR-independent mechanisms and other important hypotheses (including the functions of autophagy, $\mathrm{PCa}$ stem cell and microRNAs in CRPC progression), are summarized with retrospective pre-clinical or clinical trials to guide future research and therapy.
\end{abstract}

\section{Contents}

1. Introduction

2. Definition of CRPC

3. Androgen receptor (AR)-dependent mechanisms underlying the resistance leading to $\mathrm{CRPC}$

Correspondence to: Dr Xianhan Jiang, Department of Urology, The Fifth Affiliated Hospital of Guangzhou Medical University, 621 Gangwan Road, Guangzhou, Guangdong 510700, P.R. China E-mail: jiangxianhan@gzhmu.edu.cn

Key words: castration resistant prostate cancer, mechanism, androgen receptor splice variants, prostate stem cells, autophagy, microRNAs
4. AR by-pass signaling: Glucocorticoid receptor (GR) and progesterone receptor (PGR) expression

5. AR-independent pathways

6. Expression of microRNAs (miRNAs) in CRPC

7. Defects in DNA damage repair (DDR) in CRPC

8. Autophagy and CRPC progression

9. Prostate stem cells

10. Conclusion

\section{Introduction}

Prostate cancer $(\mathrm{PCa})$ is the most frequently diagnosed cancer in men from the Western world (1). The incidence of PCa has exceeded lung cancer, and is the second leading cause of mortality in malignant tumors in males (1). The number of novel diagnosed cases in 2016 was 180,890 in the USA alone (2). In China, the incidence of PCa is increasing year by year with the change in living habits and the aging population (3). In 2015, there were 60,300 novel cases of $\mathrm{PCa}$ and 26,600 patients with $\mathrm{PCa}$ succumbed (3). Androgen deprivation therapy (ADT) has been the primary treatment option for male patients with advanced symptomatic PCa for almost seven decades and generally results in decreased prostate specific antigen (PSA) levels. By contrast, following a median of 18-24 months of endocrine therapy, almost all patients progressed to a poor prognosis stage-castration resistant prostate cancer (CRPC), which was previously called hormone-refractory prostate cancer. However, the stage of CRPC is not hormone-refractory based on the understanding that the androgen axis continues to be activated and promotes the growth of CRPC (4). Almost all patients succumbed due to no existing treatment to control or cure the mortality-causing CRPC; therefore, the mechanisms underlying the initiation and development of CRPC remains challenging to decipher, which requires focus from international academic research, and will help to improve the survival and the quality of life of patients with PCa. In the present review, the current studies regarding the molecular and cellular mechanisms leading to CRPC are summarized for the development of future molecularly targeted therapies for PCa.

\section{Definition of CRPC}

CRPC refers to the continuous progression of PCa following ADT. In recent years, the definition of castration resistance 
has changed substantially. With the emergence of novel CRPC therapy, it is particularly important to determine the exact definition of castration resistance. In March 2015, Gallen gathered 41 experts in the field from 17 countries and regions around the world, and held the first session of the advanced $\mathrm{PCa}$ Consensus Conference (5). Almost all experts in the session agreed that the diagnosis of CRPC should meet the following 2 conditions: i) The serum testosterone level of the castrated is $<1.7 \mathrm{nmol} / \mathrm{l}$; and ii) indicating biochemical progression. Biochemical progression is characterized that the PSA expression levels have increased twice in a row from an interval of 1 week or $>3$ consecutive measurements with the lowest value increased $>50 \%$ and $>2 \mathrm{~g} / 1$, and $\geq 2$ increases in novel lesions based on bone scanning or soft tissue lesions with the corresponding evaluation criteria of the solid tumor. Currently, only symptom progression is not sufficient to diagnose CRPC. The understanding of PCa biology and underlying disease resistance mechanisms has grown over the last few decades, and has been translated into improved and clinically meaningful treatment strategies for males with advanced PCa (6). Understanding the mechanisms underlying the progression of $\mathrm{PCa}$ from hormone sensitive to castration resistant is the key to develop future therapy. In the present review, a number of the major underlying mechanisms leading to castration resistance are discussed.

\section{Androgen receptor (AR)-dependent mechanisms underlying the resistance leading to CRPC}

$A R$. The growth and survival of PCa tumors depend on androgens, the male sex steroid hormones, of which testosterone and dihydrotestosterone (DHT) are the principal members that activate and bind to the AR (7). High expression of AR occurs in the majority of patients with CRPC, and the expression of AR-regulated genes recovered in tumors after patients received ADT implies that AR transcription activity is activated again (7).

AR, as a member of the steroid hormone super family, has four functional motifs, including the ligand-binding domain (LBD), DNA-binding domain (DBD), hinge region and the amino-terminal domain (N-terminal domain, NTD) that contains the phosphorylation sites essential for transcriptional activity (8) (Fig. 1). When AR binds with a steroid ligand, including DHT, it can prevent ubiquitination and proteasome degradation by interacting with heat-shock proteins (HSP) (9). The AR is phosphorylated prior to dimerization, which leads to a conformational change, which displaces the HSP upon ligand binding (10). Dimerized ligand-bounding complex will then be transported into the nucleus (10). Ligand binding is vital to dimerization and translocation of AR to the nucleus. Following AR being trafficked into the nucleus, it may mediate transcription and various growth signaling pathways, including cellular proliferation or anti-apoptosis and androgen-regulated genes, including PSA, through binding to androgen response elements in the promoter or enhancer regions of DNA (11). A number of studies revealed that the AR may be transported into the nucleus through the microtubule complex (12). Evacuation of the ligand in androgen-responsive prostate cells results in an exportation of the AR from the nucleus (9).
In the process of hormone-responsive PCa to CRPC, the $\mathrm{AR}$ and its cross-signaling pathways exist a number of changes with various forms, which provides an important clue for the exploration of the mechanisms underlying CRPC.

Amplification of the AR gene and overexpression of the $A R$ protein. AR gene amplification and overexpression of the AR protein have been frequently observed in clinical studies. The AR gene amplification leading to an overexpression of the AR protein is the most common genetic change among patients with CRPC (13). Of the patients with CRPC, $>80 \%$ of them had significant augmentation of AR mRNA and protein levels (14). By contrast, AR gene amplification was rarely observed in untreated $\mathrm{PCa}$ (14). Research determined that the AR gene had a high frequency of amplification in circulating tumor cells (CTCs) of patients with CRPC (15). Fluorescence in situ hybridization studies utilizing tissue microarrays discovered that AR gene amplification is present in only $2 \%$ of the primary PCa tumor samples and none of the samples of benign prostatic hyperplasia, compared with $23.4 \%$ of CRPC tumors (16). Using reverse transcription-polymerase chain reaction (RT-PCR) analysis, it was confirmed that the AR gene amplification is indeed reflected at the mRNA level, where the expression of AR mRNA in CRPC tumors with AR amplification was increased two fold, compared with those CRPC tumors without AR amplification (17). On the other hand, increased AR was an unique gene expression alteration that was sustained in different CRPC xenograft tumor samples (18).

Elevated AR protein levels are also linked to CRPC. Using multiple isogenic tumor xenograft models, it was demonstrated that the expression of the AR protein increased in recurrent tumor samples, compared with paired androgen-sensitive samples $(18,19)$. Notably, in a CWR22 xenograft model that imitates the transition from androgen-sensitive to recurrent growth, the expression of the AR protein was gradually reduced during the 120-day castration period, and then regrowth occurred in recurrent tumors (19). In addition, not only was the gene amplification and elevated mRNA expression directly augmenting the AR protein levels, increased protein half-life can also contribute to the elevated levels of AR protein in CRPC (20). Through gene amplification and enhanced transcriptional induced overexpression of AR causes AR hypersensitive to low level of androgen (21). Furthermore, it can be concluded that under the lowest concentration of androgens, tumor cells proliferate continuously (22), which indicated that overexpression of AR may contribute to the development of CRPC formation.

AR mutations. AR mutations in the early stage of $\mathrm{PCa}$ are rare, but it is commonly occurs in CRPC, particularly advanced $\mathrm{PCa}$ following systematic hormone therapy. There are $>100$ point mutations that appear in AR, and the majority of them present in the NTD or LBD region $(4,23)$. In recent years, there are a number of studies regarding AR mutations including T878A, H875Y/T, W742C, L702H and F877L (24-26). The mutations in the hinge and LBD regions of AR result in increased AR transactivation activity and decreased ligand specificity. A large number of AR mutations can be activated by adrenal androgens and other steroid hormones; additionally, a number 
A

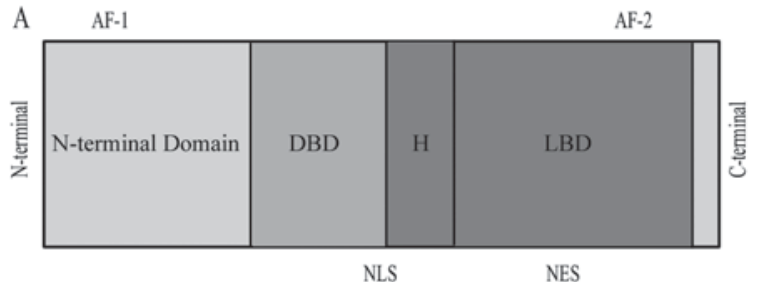

B

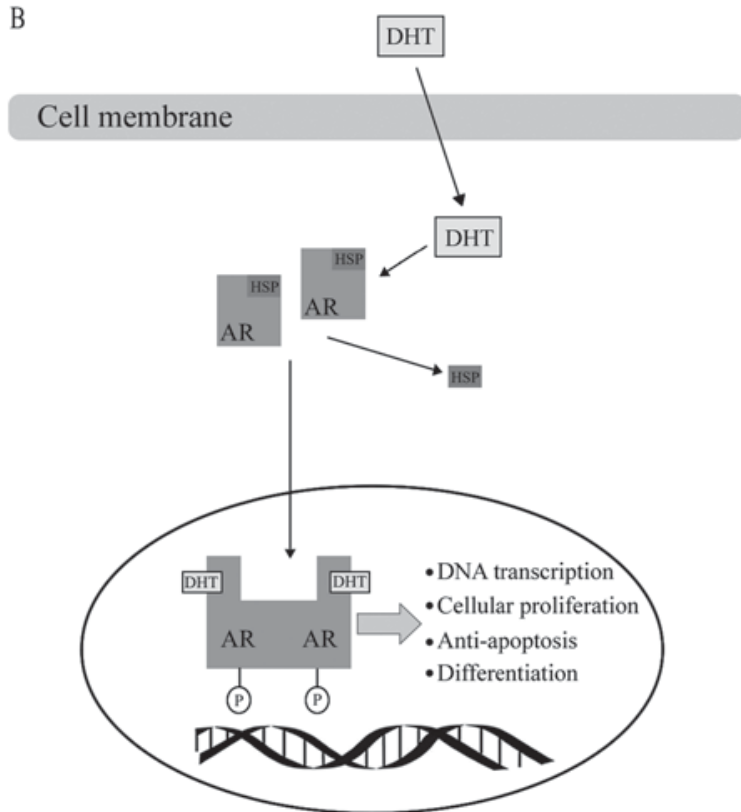

Figure 1. (A) Functional domains of the AR. (B) Biology of the androgen receptor signaling pathway. DBD, DNA binding domain; LBD, Ligand binding domain; $\mathrm{H}$, hinge region, $\mathrm{AF}-1$, transcriptional activating function 1 ; AF-2, transcriptional activating function 2; NLS, nuclear localization signal; NES, nuclear export signal; AR, androgen receptor; DHT, dihydrotestosterone; HSP, heat-shock protein; $\mathrm{P}$, phosphorylation.

of mutations can turn AR antagonists (flutamide and bicalutamide) into potential agonists. Compared with endocrine therapy, AR antagonists in the treatment of metastatic $\mathrm{PCa}$ will cause the rate of $A R$ mutations in the $\mathrm{LBD}$ region to be increased.

The T878A mutation is one of the most common forms of AR mutations. It was found that the AR T878A mutation occurs in patients with CRPC following prolonged ADT; however, not hormone-sensitive patients (27-29). Furthermore, it has been reported that this mutant was expressed in the tumors of patients with CRPC whose PSA levels were significantly decreased by flutamide withdrawal (29). This discovery has led to the hypothesis that expression of the AR T878A mutation is responsible to the beneficial effect of withdrawing anti-androgen therapy in patients with CRPC. This mutation also leads to an expansion of binding specificity of the ligand of AR, improving the sensitivity of steroid hormones such as progesterone and estrogen (30). A number of the mutations can turn the anti-androgen substances into agonists. For example, the F877L mutation activated by enzalutamide or ARN-509 has been demonstrated to transform AR antagonists into AR agonists in a PCa cell line following long-term treatment with enzalutamide and ARN-509 (31). Recent studies indicated that the mutations T878A, H875T/Y, W742C and L702H exist in $15-20 \%$ of CRPC tumor samples, which emphasized that the LBD region is a mutational hotspot (32). Utilizing circulating free DNA from patients with CRPC, which has been determined to contain genomic DNA with the AR mutations, demonstrated that using sequencing to detect those point mutations aforementioned could possibly act as biomarkers for patients at risk of developing CRPC (33). Additionally, combination therapy may overcome part of the secondary resistance with AR mutations, an ongoing clinical trial (34), using combination therapy of abiraterone and enzalutamide in patients with CRPC may demonstrate this hypothesis. If those studies using blood-based detection to distinguish AR mutations in patients with CRPC are clinically validated, then clinicians may have accessible biomarkers for individual treatment selection, which may improve the clinical outcome for patients.

Expression of AR splice variants $(A R-V s)$. AR-Vs have been demonstrated to be associated with resistance to ADT of PCa as well as the resistance to abiraterone and enzalutamide (35). AR-Vs are truncated forms of AR, which lack the LBD region, where just the NTD and DBD regions were transcriptionally activated, independent of the presence or absence of ligand-binding or antagonist effect (36). Hu et al (37) explored the AR intronic sequences in the human expressed sequence database, and determined that CE 1-4 and identified AR variants (AR-V 1-7) lacked the LBD region. This trait of ligand-independence makes truncated AR variants potentially important to disease progression and patient treatment response, as they can activate AR target genes independent of the androgen (36). The current studies discovered splice variants include AR3, AR4, AR5 and AR-V1V7 (38). The AR transcripts AR-V3 and AR-V4 have the same sequences to AR $1 / 2 / 2 b$ and AR $1 / 2 / 3 / 2 b$; therefore, novel variants were identified as AR-V1, AR-V2, AR-V5, AR-V6 and AR-V7 (39). A number of the AR-Vs (including AR-V7) primarily localize in the nucleus, while others (including AR-V1, AR-V4 and AR-V6) localize mainly in the cytoplasm. Notably, cytoplasm-predominant AR-Vs frequently co-expressed with the nucleus-predominant AR-Vs as well as the full-length AR (AR-FL) (40). Not only are AR-Vs predominantly products of alternative splicing, but also can they be products of nonsense mutations (ARQ640X) or proteolytic cleavage (41) (Fig. 2).

Detected at the mRNA and protein levels, AR-V7 is the most frequently studied and abundant AR variants in clinical samples from patients with CRPC (42). A retrospective study have indicated that the presence of AR-V7 was associated with more advanced malignance and reduced survival in patients with metastatic CRPC (mCRPC) (43). Previously, the study of Antonarakis et al (44) have carried out a prospective study, which utilized CTC samples of patients receiving abiraterone or enzalutamide therapy to evaluate the prognostic role of AR-V7 detected at the mRNA levels by RT-PCR. They discovered that compared with those patients without detectable circulating AR-V7, the appearance of AR-V7 in CTCs was associated with lower PSA response rate, reduced progression-free-survival (PFS) and reduced overall survival (OS) (44). Notably, the level of AR-V7 was higher in males who had been treated with enzalutamide and abiraterone, whilst the level of AR-V7 was lowest in males who had not received either agent therapy. In addition, when analyzing 


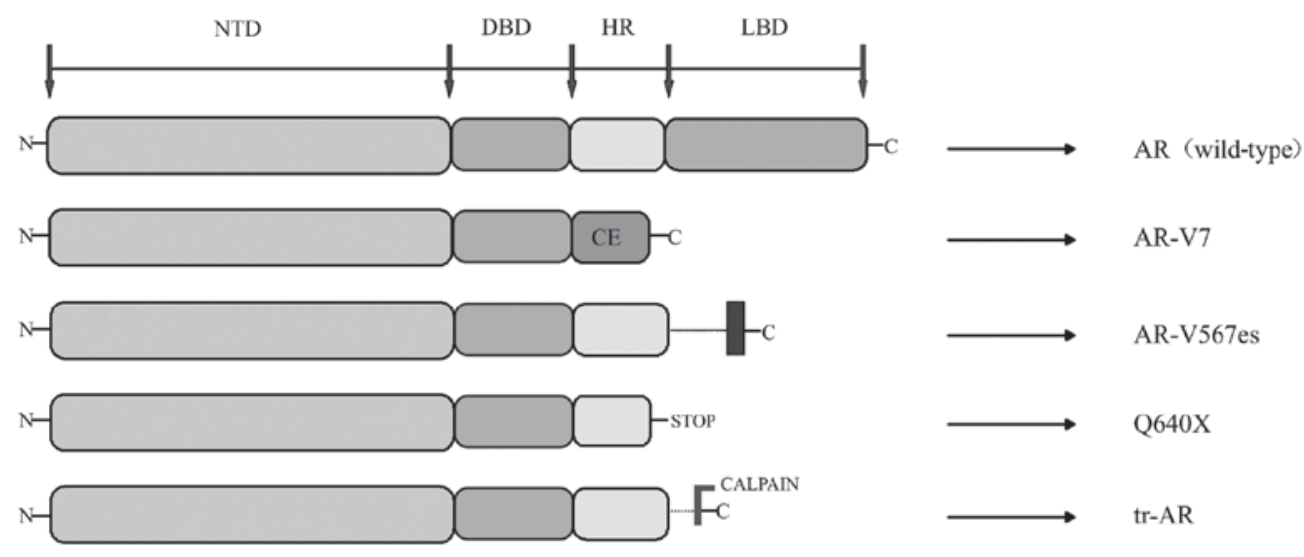

Figure 2. Functional domains of the AR variants. AR, full length AR wild type; AR-V7, product of alternative splicing, CE; ARv567es, product of altered splicing, exon 5,6 and 7 skipped during splicing; Q640X, AR with a nonsense mutation leading to a tr-AR of 640 aa; enzymatically cleaved by calpain. AR, androgen receptor; DBD, DNA-binding domain; LBD, ligand-binding domain; PCa, prostate cancer; CE, cryptic exon; tr-AR, truncated AR; AR-V, AR splice variants; NTD, N-terminal domain; HR, hinge region.

serial CTCs over time, the study demonstrated that all males with a baseline of AR-V7 remained AR-V7 positive during the process of abiraterone and enzalutamide therapy, whereas $14 \%$ of males with negative AR-V7 level at baseline changed to AR-V7 positive during treatment, and these patients had an intermediate clinical outcome (44).

It was confirmed that AR-V1, AR-V4 and AR-V6 can dimerize with AR-V7 and AR-FL; therefore, AR-V7 and androgen-bound AR-FL induced nuclear localization of AR-V1, AR-V4 and AR-V6. Additionally, these variants weakened the efficiency of enzalutamide to inhibit androgen-induced AR-FL nuclear localization. It is notable that the impact of nuclear localization of AR-V4 and AR-V6 on AR transactivation differs from that of AR-V1 (45). Nuclear localization results in an enhanced ability of AR-V4 and AR-V6 to transactivate canonical AR targets and AR variants specific targets, and promote castration resistant cell growth (45); however, when AR-V1, which lacks inherent transcriptional activity, activates AR-FL in an androgen-independent way, it significantly inhibits AR-V7 transactivation (45). These data illustrated the important role of complicated interactions among different AR-Vs and AR-FL in castration resistant disease, and dissecting these complex interactions may help to develop effective strategies to target AR variants signaling (45). In recent research, AR-NTD targeting drugs have benefits over drugs targeting the AR-LBD due to the NTD being essential for the transcriptional activities of AR-FL and AR-Vs; therefore, AR-NTD antagonists, including EPI-002, patients who are resistant to abiraterone or anti-androgens with constitutive activated expression of AR-Vs could achieve therapeutic responses from EPI-002 $(46,47)$. As a result, with gradual clarification of the AR-Vs formation, it has a possibility to become a novel targeted therapy for the treatment of patients with CRPC in the future.

Altered expression and function of AR co-regulators. AR co-regulators are protein factors, which were associated with AR transcription activation, and serve an auxiliary role in activation or inhibition of AR-mediated transcription (48). AR co-regulators have the function of activating transcription activity of AR under an extremely low concentration of androgens (48). It has also been demonstrated that co-regulator factors serve an important role in the development of CRPC formation. Normally, AR recruits a series of co-regulator complexes, which can either enhance or repress transcriptional activity. Many of these co-regulators are enzymes that serve to modulate other proteins through phosphorylation, methylation, acetylation or ubiquitylation, in a complex form $(49,50)$. They have also been identified as molecular chaperones, recruiters of transcriptional machinery and RNA splicing regulators $(49,50)$. According to their different effects on AR transcription, AR co-regulators can be divided into co-activators [including P160/SRC and p300/CREB binding protein (CBP)], co-repressors (including NcoR 1 and NcoR 2), pioneer factors (including forkhead box A1, GATA2 and cardiotrophin 1) and cooperators (including ETS-1, adaptor associated protein complex 4 and NKX3-1) (51-55). There are $>150$ different molecules that have already been identified as co-activators or co-repressors of AR (56). When AR interacts with a co-activator, it can lead to a significant abnormal activation of AR, which results in increased AR transcriptional activity (50); therefore, changing the ability of AR transcriptional activation is essential for AR to achieve the maximum transcriptional effect. For example, FKBP51, as an AR target gene and a co-activator of $\mathrm{AR}$, was determined to be upregulated in relapsed LAPC-4 tumors that were grown in castrated mice (57). The formation of a super chaperone complex was improved by FKBP51 via recruiting p23, to adenosine 5'-triphosphate (ATP)-bound Hsp90, which in turn keeps $\mathrm{AR}$ in a conformation with high affinity for ligand-binding, thus promoting androgen-induced transcriptional activity and growth (58). Other important pathways, including p300/CBP, which promotes androgen-independent interleukin (IL)-6 mediated AR activation in the presence of the signal transducer and activator of transcription 3 (STAT3), lysine demethylase 1A (LSD1A), jumonji domain-containing 2c (JMJD2c) and lysine demethylase that demethylates the histone $\mathrm{H} 3$ proteins and then promotes AR induced transcription (59). On the other hand, when AR is combined with co-repressor, the opposite effect occurs in reducing the AR transcriptional activity, although they have been observed at decreased levels in CRPC (60). Additionally, the majority of cooperators serve 
the role of increasing the AR transcription, whilst pioneer factors can interact with condensed chromatin and directly regulate the accessibility of chromatin (61). It is important that the interaction between pioneer factors and chromatin is prior to the androgen induction, which means that these factors can direct AR to chromatin aggregation at low or no levels of androgens $(54,55)$.

Aberrant post-translational modifications of $A R$. Post-translational modifications of AR mainly include acetylation, methylation, ubiquitination, sumoylation and phosphorylation (62). The molecular effects of these transformations induce decreased apoptosis and elevated transcriptional activity to the androgen-responsive genes (62). Research indicated that hypomethylating drugs can be used as a treatment in delaying the appearance of CRPC (63). Inhibiting DNA methylation can reverse the mechanism underlying castration resistance, the potential underlying mechanism may be associated with the downregulation of DNA methyltransferase 1-dependent STAT3 activity. Many serine/threonine and tyrosine kinases are involved in AR phosphorylation, including Aurora-A, PIM1 kinase, cyclin-dependent kinase 1 (CDK1), Src and Ack1 (64-67). Aurora kinase (68) is the most extensively studied clinically. In a phase II trial (69), 60 randomly selected patients with $\mathrm{mCR} P C$ were randomized into two different treatment schedules based on using danusertib or not, an inhibitor of Aurora kinase. All of the patients had been previously treated with docetaxel. Only two patients had a PSA response, and the best radiographic response was an indicated stable disease in $27 \%$ of patients. The median PFS was 12 weeks in both groups Due to of the disappointing results, no further research on this compound is being pursued. The study indicated that aurora kinase was upregulated in anaplastic or neuroendocrine PCa (708) More recent clinical trials (NCT01799278 and NCT01848067) are using these agents to target the small cell and anaplastic PCa. Research for these targets is actively continuing, although no late-phase clinical trials are currently planned or ongoing. These phosphorylation modifications, which enable AR to respond to low levels of androgen, and being the targets of small molecule inhibitors could be a promising treatment for patients with CRPC.

Synthesis of adrenal androgens and intratumoral androgens. Normally, testosterone mainly originates from the testes, with $5-10 \%$ coming from adrenal glands. In general, medical or surgical castration can reduce circulating levels of serum testosterone by $>90 \%$ to maintain its circulating concentration below normal levels of castration (1.25 $\mathrm{pmol} \mathrm{g}^{-1}$ ) (70); however, androgen concentration in prostate tissues remains sufficient for activation of AR (70). The androgen concentration in prostate tissues is significantly lower than that of serum androgen in patients following ADT (71). PCa may act as synthetic androgen within tissues through a number of unknown mechanisms; therefore, PCa tissues can synthesize androgen using prostate tissues and not rely on androgen cycle following ADT, and this condition may result in failure of the procedure (71). Recently, utilizing autopsy and tissue biopsy studies to compare androgen levels in hormone-sensitive and hormone-resistant tumors from patients has revealed high levels of continuous androgen production in tumor tissues of patients with CRPC (72). Studies have considered that sustained production of androgen within prostate tissues possibly results from the conversion of weak-bioactivity androgen-like androstendione (AD) and dehydroepiandrosterone (DHEA) $(73,74)$, which are produced by adrenal glands or de novo steroidogenesis of androgen from the cholesterol within tumor tissues (74). Although circulations of AD and DHEA significantly decrease in patients with CRPC following treatment with abiraterone (CYP17 inhibition), a sustained pool of DHEA-S, which is a sulfated form of DHEA, and the predominant adrenal androgen in circulation can serve as precursors for transformation into testosterone and DHT in prostate tissues (75). The role of intratumoral androgen in promoting CRPC cells growth was proven by large phase III clinical trials, which aimed to test the testosterone concentration of tumors in patients receiving novel anti-androgen therapies of enzalutamide and abiraterone $(76,77)$. All patients with $\mathrm{mCRPC}$ were tested and indicated improved OS, compared with those who received placebo treatment.

Fig. 3 summarizes the majority of mechanisms mediated by $\mathrm{AR}$ or androgen axis leading to CRPC into several subsets (78).

\section{AR by-pass signaling: Glucocorticoid receptor (GR) and progesterone receptor (PGR) expression}

Steroid receptors, including AR, estrogen receptor- $\alpha$, estrogen receptor- $\beta$, PGR, GR and mineralocorticoid receptor, are derived from the same material and feature high homology, particularly in the DBD binding region (79). GR and PR are more relevant to AR (80). Almost all PCa were discovered to express AR, whereas GR is only present in $30 \%$ of PCa cases; however, GR expression increases in patients following ADT (81). Recent studies have indicated that AR and GR possess the same chromatin binding sites and regulate the expression of a large number of AR-specific genes (82). Resistance of enzalutamide to novel AR antagonist may be due to increased expression of GR. ADT can increase GR expression and demonstrated the potential for GR signaling $(68,83)$. GR can also act as a substitute for AR signaling. Montgomery et al have summarized a series of clinical trials to assess the contributions of glucocorticoids and GR in patients with CRPC $(84,85)$. In these trials, analysis of patients in clinical cohorts who received glucocorticoids indicated poor prognostic features, compared with patients who did not receive such treatment; therefore, stimulation of GR signaling may pose negative effects to patients who have received androgen-targeted therapies (84-86). In such conditions, the presence of increased glucocorticoids in serum and absence of androgen possibly enables the selection of 'promiscuous' AR variants with mutations in the LBD, allowing their activation by glucocorticoids (87); therefore, GR or other nuclear steroid receptors can bypass AR pathways and promote the development of CRPC.

On the other hand, PGR is also a member of the steroid hormone nuclear receptor family, and it is structurally associated with AR. As with GR, PR may have the ability to transcriptionally regulate a subset of AR target genes in PCa and thereby 


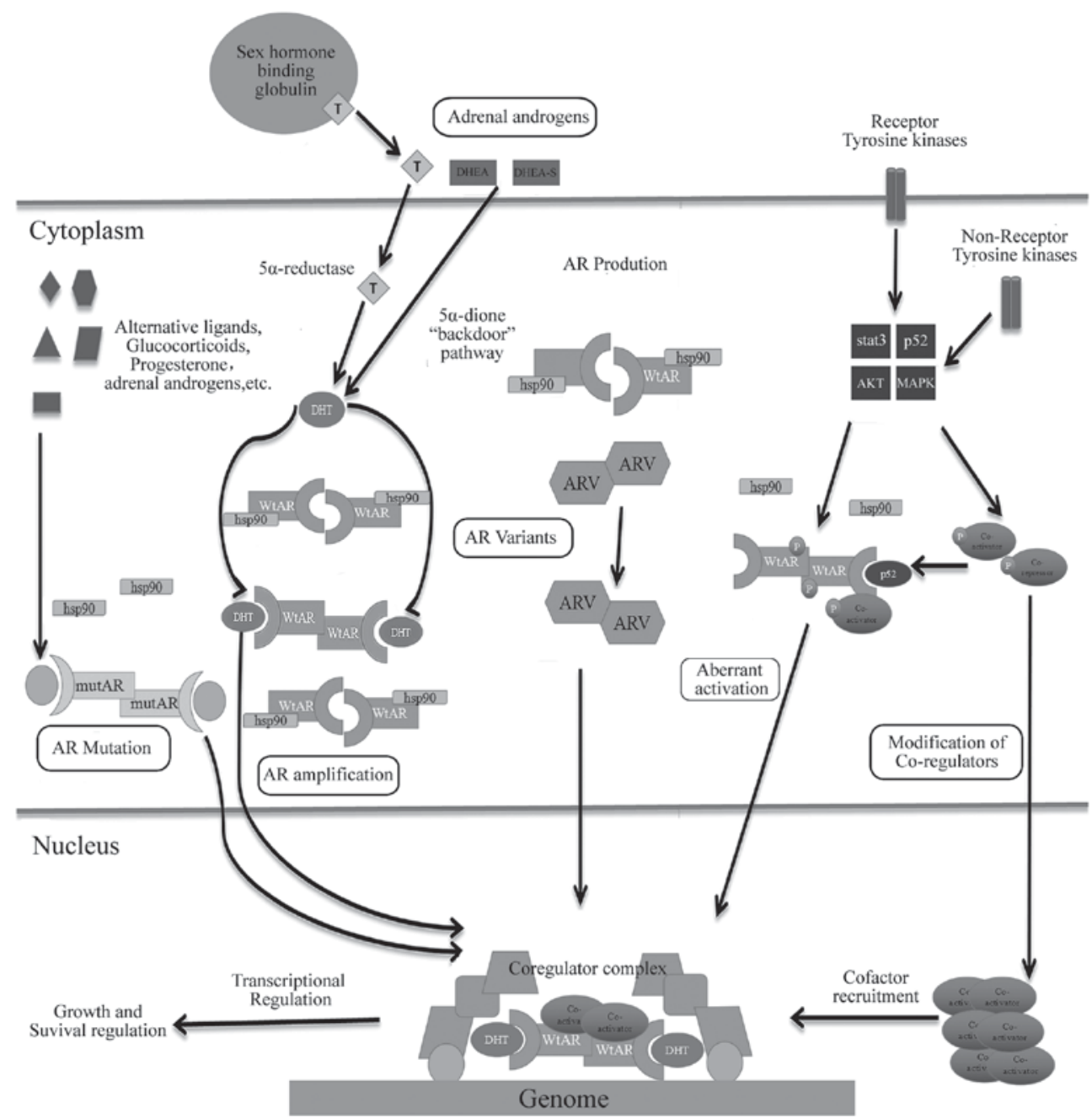

Figure 3. Androgen receptor-dependent mechanisms of resistance in hormone-sensitive prostate cancer leading to castration-resistance. AR, androgen receptor; wtAR, wild-type AR; AR-V, AR splice variants; mutAR, mutated AR; T, testosterone; DHT, dihydrotestosterone; DHEA, dehydroepiandrosterone; STAT3, signal transducer and activator of transcription 3; MAPK, mitogen-activated protein kinase; HSP, heat-shock protein.

bypass AR (88). A large retrospective analysis carried out recently demonstrated the association of high PR staining in primary $\mathrm{PCa}$ with its clinical recurrence (89). A recent research on a cohort of $>500$ patients also revealed the association of high PR expression in cancer cells with reduced clinical failure-free survival (89). This evidence indicated that PR antagonists may possess therapeutic effects, indicating that PR signaling can be an important carcinogenic target in the treatment of PCa.

\section{AR-independent pathways}

Phosphoinositide 3-kinase-protein kinase B-mechanistic target of rapamycin (PI3K-Akt-mTOR) pathway and CRPC. The PI3K-Akt-mTOR pathway has been known as a potential driver of CRPC. PI3K is activated by G protein-coupled receptors or tyrosine kinase receptors. Activation of PI3K leads to phosphorylation of AKT and activation of mTOR and subsequent downstream effects, including cellular proliferation, survival and angiogenesis $(90,91)$. Previous studies have demonstrated that alterations of components in the PI3K-Akt-mTOR pathway occur in $100 \%$ of metastatic tumors and $42 \%$ of primary prostate tumors $(4,91,92)$; therefore, targeting the PI3K-Akt-mTOR pathway is considered a promising therapeutic approach for patients with CRPC. Loss of the phosphatase and tensin homolog (PTEN) gene has been frequently proven to result in constituting activation of the PI3K-Akt-mTOR pathway in the majority of advanced PCa cases (93). A recent study used either targeted drugs or gene knockout in mouse models, whereas cell lines have indicated alterations in PI3K and PTEN activities, demonstrating changes in AR expression and AR transcriptional activity (94). Kato et al (92) reported the combined use of the AR-V inhibitor EPI-002 and PI3K/mTOR inhibitor BEZ235 to evaluate their therapeutic efficacy on LNCaP95 cells in CRPC models in vitro and in vivo. Results demonstrated that compared with single drug cohorts, drug combination can significantly inhibit LNCaP95 cell growth without increasing toxicity. These data indicated that co-targeting the PI3K-Akt-mTOR pathway and AR-NTD to block AR-FL and AR-Vs can be a novel approach for achieving improved antitumor efficacy for patients with CRPC who have indicated resistance to abiraterone or other anti-androgen treatments by a mechanism involving expression of AR-Vs.

Src signaling pathway and its inhibitors. The Src kinase family (SFK) comprises of proteins with protein tyrosine kinase. Src kinase activation has been indicated to be relevant to 
androgen-independent cell growth, inhibition of anti-apoptotic pathways, cell migration and adhesion and tumor invasion. In $\mathrm{PCa}$, Src signaling upregulates vascular endothelial growth factor (VEGF) and IL-8 to promote angiogenesis (95) and activates the nuclear factor-KB pathway of osteoclasts and various tumor necrosis factor receptors involved in resistance to apoptosis signal transmission to participate in bone metastasis of PCa (95). Dasatinib, an inhibitor of Src kinases, has been confirmed to slow down the growth of PCa tumors and to be as effective as CRPC treatment based on a phase III clinical trial (96). Saraeatinib (AZD-0530) is a dual inhibitor of Src and Abl, and the research of Yang et al (97) demonstrated that this drug can inhibit proliferation and invasion in bone metastasis models of PC 3 cell lines and alleviate bone destruction; a phase II clinical trial with Saraeatinib is currently ongoing.

Growth factor pathways. Activation of the growth factor signaling pathway can also enhance AR signaling pathway and promote CRPC. Growth factor receptors, including insulin-like growth factor I receptor, IL-6 receptor and epidermal growth factor receptor, can mediate the growth of critical downstream pathways, including mitogen-activated protein kinase (MAPK), PI3K/AKT and signal transducer and activator of transcription signaling (98). Activation of PI3K-Akt and Ras-Raf-MAPK pathway and expression of receptor tyrosine kinases, including Her-2/neu, have already been observed to enhance AR stability and activity in CRPC samples (99). A previous study demonstrated that Her-2/neu promotes the growth of xenograft cells and androgen independence through Ack1-kinase, which phosphorylates AR at tyrosine-267 and activates AR activity (100). Targeting growth factor signaling pathways has provided a novel therapeutic strategy. In a phase II clinical trial (101), application of cabozantinib (XL-184), an inhibitor of tyrosine kinase of c-Met and VEGF, resulted in PFS of 23.9 weeks in patients with CRPC, whereas the placebo group yielded a PFS of 5.9 weeks. Following treatment with cabozantinib for 12 weeks, bone scan of $68 \%$ of patients indicated improvement; whereas, results for $12 \%$ of patients demonstrated that bone metastatic lesions completely subsided. XL-184 can also relieve pain of patients with CRPC to improve their quality of life (101).

\section{Expression of microRNAs (miRNAs) in CRPC}

miRNAs are small, non-encoding, and conserved genetic single-stranded RNAs. miRNAs can target gene mRNA 3' untranslated region through complete or incomplete complementary binding, resulting in degradation of target gene mRNA or inhibition of translation; which functions as a gene expression regulation factor in cell metabolism, proliferation, differentiation and cell death and cell survival $(102,103)$.

Extensive research indicated that expression profiles of miRNAs in PCa become increasingly important due to of their application in diagnosis, staging, predicting prognosis and response to the treatment (104). An earlier study confirmed upregulation of miRNA-96, -182, -183 and -375 and downregulation of miRNA-16, -31, -125b, -145, -149, $-181 b,-184,-205,-221$ and -222 in PCa tumor tissues (105).
In a recent study, using miRNA microarray to detect miRNA expression between primary PCa tumors and CRPC tumors has indicated divergent results, where 75 miRNAs were differentially expressed in primary PCa, 88 in CRPC tumors, and 22 changed expressions of miRNAs overlapping between primary and CRPC samples (106). Altogether, these data implicate that changes in miRNA expression can contribute to resistance to ADT.

The most frequently studied miRNAs associated with PCa progression include miRNA-16, miRNA-34a/34b, miRNA-143, miRNA-101 and miRNA-200c. Cell experiments indicated that exogenous expression of miRNA-16 can inhibit the recurrent growth of 22Rv1 cells, androgen-independent DU145 cells and PC3 cells, but not androgen-dependent LNCaP cells (107). miRNA-34a has been demonstrated to specifically downregulate AR expression (108), indicating that loss of miRNA-34a can increase AR expression, as observed in PCa cell lines, xenograft models and human CRPC tumors (17). Observation of patient with PCa samples has demonstrated that high miRNA-34b expression is correlated with longer OS, whereas the opposite is correlated with higher Gleason score $(15-17,109)$. One assumption indicated that induced miRNA-34b expression can increase the aggressiveness of PCa. Expression levels of miRNA-200c were significantly reduced in primary PCa tumors of patients who relapsed following prostatectomy, compared with those without relapse (110). miRNA-101 expressions notably decreased in metastatic tumors, compared with those of primary samples (111). All these data implicated that miRNAs cannot only potentially promote tumor progression and sustain resistance to ADT but also act as biomarkers for patient outcomes. Analysis of radical prostatectomy specimens indicated that miRNA-301a, miRNA-449b and miRNA-182 can act as biomarkers to predict biochemical recurrence following prostatectomy (112-114). Recently, combining Gleason scores and lymph node status with expression levels of miRNA-4516 and miRNA-601 has demonstrated predictive roles of these miRNAs in biochemical recurrence following post-prostatectomy salvage radiation therapy (115), supporting the utilization of miRNAs in clinically used predictive models.

In conclusion, miRNAs serve important roles in initial PCa pathogenesis, progression and development of CRPC. miRNAs can also function as attractive biomarkers due to they are relatively stable in biological fluids, easy to measure and are resistant to storage handling (104); therefore, abnormal levels of expressed miRNA in tumor tissues, serum or plasma and urine can be a promising biomarker for diagnosis, prognostic prediction, or treatment efficacy of patients with $\mathrm{PCa}$.

\section{Defects in DNA damage repair (DDR) in CRPC}

Defects and mutations in DDR genes have been reported in CRPC and in localized aggressive cancers (116). For example, mutations and loss of BRCA2 were observed in $12 \%$ of PCa cases (117). Germline mutations in BRCA increase the probability of lymph node involvement and distant metastases, which confer PCa with more aggressive phenotypes (118). CRPC frequently features homologous DNA recombination function deletion, expression of TMPRSS2-ERG gene fusion and the DDR protein poly (ADP-ribose) polymerase (PARP)-1, 
which is recruited to sites of AR targets and serves an important role in AR transcription, which is essential for the activity of TMPRSS2-EGR in PCa (119). In a phase II trial (120), patients who had recurred following $>2$ rounds of CRPC therapies were treated with olaparib, a PARP inhibitor and a base excision repair protein. Results demonstrated that patients who exhibited genomic defects in DNA repair genes (including BRCA1, BRCA2 and ATM) manifested a 6.3-month increase in OS, compared with those without these defects. These results indicated that blockade of DNA damage response may promote CRPC, whereas genomic instability improves responsiveness of patients with CRPC to treatment for target DNA repair (120).

AR indicated potential links with DDR. By using a combination of anti-androgen therapy and radiotherapy to treat aggressive PCa, large clinical trials demonstrated significant augmentation in efficacy, indicating the potential role for AR inhibition in weakening DDR $(121,122)$. AR enhances the expression and activity of key DDR factors, including DNA-dependent protein kinase (DNAPK); in turn, DNAPK sustains AR transcription (122). ADT induces reduction in transcription of key DDR genes, resulting in higher levels of DNA damage following radiotherapy, specifically non-homologous end-joining (121). Such results indicated that ADT affects genomic instability prior to castration or promotes development of CRPC through repressing DDR. MYB protein was observed to replace AR function in regulating DDR by modulating an overlapping set of genes. Silencing of MYB gene or a number of its targets (TOPB1, ATR and checkpoint kinase 1) synergizes with PARP inhibitor olaparib, and such condition can significantly suppress $\mathrm{PCa}$ growth in in vitro and in vivo experiments and increase cytotoxicity of PCa (123); therefore, combination of MYB pathway inhibitor and PARP activity suppressor can be a viable clinical strategy.

\section{Autophagy and CRPC progression}

Autophagy is a genetically programmed cellular stress regulation mechanism occurring in all eukaryotic cells. This process is one of the major protein degradation processes that prevail through the lysosomal pathway (124). Autophagy mediates the clearance of damaged organelles and long-lived proteins, leading to the formation of double-membrane structures called autophagosomes (Fig. 4). Cells can recycle amino acids and other macromolecular materials for biosynthesis via autophagy. Normal cells clear chemical carcinogens and impaired organelles caused by radiation or oxidative stress mainly through the action of mitochondria, thereby protecting cell DNA against damage from reactive oxygen species, ensuring genomic stability and reducing incidence of cell malignant transformation (125); therefore, autophagy is crucial in maintaining hereditary stability.

Recent studies indicated that autophagy may be associated with resistance to chemotherapy in malignant tumors. For example, the studies of Jiang et al $(126,127)$ have reported that overexpression of mitochondrion-associated leucine-rich pentatricopeptide repeat motif-containing protein, an inhibitor of autophagy, and low levels of autophagy activator microtubule-associated protein 1S (MAP1S), a member of MAP1 family, can be both used as independent biomarkers for patients with late-stage $\mathrm{PCa}$ and poor prognosis. Patients receiving multiple chemotherapy, particularly for oxygen-deprived tumor cells, demonstrated significant increase in the degree of nutrient limitation. Ischemia, hypoxia and lack of nutrition can activate autophagy. Autophagy modifies metabolism by degradation and recycling of intracellular substances. Through this mechanism, tumor cells can induce adaptive responses to stress and survive. In the late stage of tumor progression, autophagy becomes an important survival mechanism for tumor cells that cannot directly obtain nutrition from circulation in the central body of solid tumors $(128,129)$. Facial tumors and those determined that have poor living environments can eliminate large molecules or mitochondria damaged by ionizing radiation and cell toxicity through enhancing autophagic activity and blocking transmission of the mitochondrial apoptosis signal cascade (129). Autophagy can also prevent pro-apoptotic factors, including cytochrome and apoptosis-inducing factor diffusion by separating mitochondria. These mechanisms may form a resistance of tumor cells to radiotherapy and chemotherapy and prevent their apoptosis. Patients with CRPC frequently use chemotherapy based on docetaxel and mitoxantrone as palliative therapy. However, with repeated administration, resistance to chemotherapy becomes prevalent in patients, but overall effect is poor $(130,131)$. Existing studies imply that autophagy serves an important role in development of CRPC (130-133).

Using enzalutamide to block AR as a long-term treatment can activate AMP-dependent protein kinase [AMP-activated protein kinase (AMPK)], whereas mTOR is inhibited by mTOR mudulin $(132,133)$. Studies have indicated that AMPK can directly regulate mTOR activities to match energy imbalance, thus increasing the ratio of AMP/ATP $(132,133)$. Hypoxia is one of the indirect causes by which anti-androgen therapy can improve autophagic activities (130), whereas blockage of angiogenesis by androgen withdrawal and nutrient synthesis under hypoxia further stimulates autophagy. The information aforementioned can confirm the effects of AR on autophagy surges but fail to fully elucidate autophagy mechanisms. For example, ADT can still be used to develop PC3 cells that lack AR for upregulating autophagy (132). Possible reasons include changes in proto-oncogenes, including PTEN, altered tumor suppressor genes, including cell tumor antigen P53 and abnormal metabolism of AR downstream (134). Bennett et al (131) indicated that the use of synergistic autophagy inhibitor 3-methyladenine with bicalutamide results in 1.5-fold higher cell mortality rate than using bicalutamide alone. Colquhoun et al (135) also demonstrated that using bicalutamide with metformin in treating LNCaP cells will significantly decrease the colony formation rate. This phenomenon also occurs in PC3 cell lines although the latter requires higher doses. Notte et al (136) discovered that two key pathways of taxol inducing autophagy; the first is paclitaxel-inhibited mTOR, whereas the second participates in activation of c-Jun N-terminal kinase, Bcl-2 and Bcl-XL phosphorylation and activation of autophagy. Notably, although these pathways perform similar functions, treatment time with paclitaxel and environmental pressures required for activation of autophagy remarkably differ. LNCaP-AI is an androgen-dependent PCa cell line. When cultured in an androgen-deficient environment, tolerance of the LNCaP-AI cell line to docetaxel is 2.5 times greater than that of common LNCaP cell lines (131). Recovery of androgen of the LNCaP-AI cell line in culture medium also indicated sensitivity to 


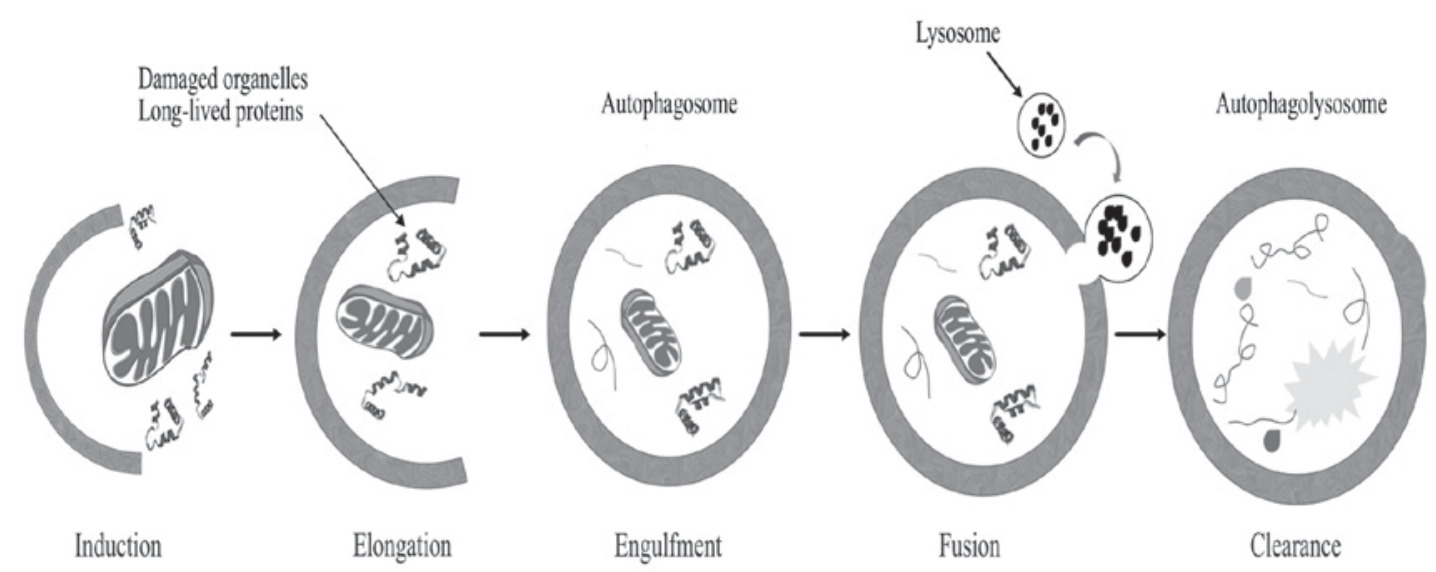

Figure 4. Schematic representation of the autophagy pathway.

docetaxel (131). When re-adding 3-methyladenine to inhibit autophagy, cytotoxicity of docetaxel increases; thus, autophagy is a factor influencing docetaxel resistance (131).

Kinases serve important roles in the metabolism and proliferation of PCa cells and thus affect the progression of the disease. A previous study established PCa models in xenogeneic mice, with one group receiving saracatinib treatment and another receiving saracatinib combined with chloroquine treatment. Following 14 days of observation, the rate of tumor growth inhibition reached $64 \%$, whereas that of single-saracatinib group totaled 26\% (137). Current limitation of inhibitors of SFK may be due to simultaneous emergence of therapeutic effects and therapeutic resistance caused by overlapping molecular pathways (137). An autophagy inhibitor may overcome this limitation.

At present, many clinical trials focus on regulation of autophagy in PCa. However, regulation of autophagy still lacks specificity, and influences on non-tumor tissues are also uncertain. In the future, the aim is to gain further insights into dynamic changes in autophagy during PCa development and treatment. Through specific autophagy regulation, inducing cell apoptosis and malignization may be a viable strategy for treatment of PCa.

\section{Prostate stem cells}

Stem cells are a type of cell that indicate multiple differentiation potential, self-renewal, absence of differentiation or low differentiation and exist in multicellular organisms (138). In recent years, constant research demonstrated that prostate stem cells are closely associated with the occurrence and development of PCa. Prostate epithelial stem cells exist in the basal layer, which generates intermediate amplification cells, resulting in highly differentiated luminal epithelial cells of the prostate (139). Mesenchymal stem cells exist in the prostatic stroma, and they are induced by the microenvironment to generate various prostate stromal cells, including fibroblasts and muscle cells. Prostate epithelial stem cells and mesenchymal stem cells do not depend on the presence of androgen but can respond to this hormone $(139,140)$. Using Hoechst33342 staining, Rupesh first isolated prostate stem cells in 2003. Richardson et al (141) confirmed that $\sim 1 \%$ of human prostate basal cells express cell surface markers, CD133, cells with phenotype of $\alpha 2 \beta 1$ and hi/CD133+ possess high proliferative potential in vitro and can reconstruct prostatic acini in immunodeficient male nude mice. A previous study also isolated a type of PCa cell similar to prostatic basal cells from androgen-dependent PCa; these cells can also survive without androgen (140). The study of Collins et al (142) successfully isolated PCa stem cells with the phenotype of CD44+/ $22 \beta 1$ hi/CD133+ from PCa tissues utilizing a transplantation assay based on isolated cells xenografted into immunodeficient mice; they first proved the existence of PCa stem cells, and this result may explain why patients with PCa will indicate potential castration resistance and metastasis following ADT.

PCa stem cells are generally believed to be caused by mutations of prostate stem cells, and development of $\mathrm{PCa}$ is possibly associated with mutations in stem cells of the prostate (143). Stem cells from PCa or the normal prostate possess unlimited self-renewal ability and the capacity for multipotential differentiation, they improve self-protection through a variety of ways, including anti apoptosis. Stem cells activate membrane transport proteins and strengthen DNA repair capacity and they differentiate into cancer tissues similar to primary prostate carcinoma following transplantation in vitro (138). However, PCa stem cells and prostate stem cells also exhibit differences. Normal prostate stem cell proliferation is frequently associated with tissue damage or other conditions, whereas malignant proliferation of PCa stem cell is usually associated with loss of body control $(140,144)$. By contrast, normal prostate stem cells can differentiate into mature tissues and perform corresponding functions unlike PCa stem cells, which can only differentiate and maturate. Compared with normal prostate stem cells, PCa stem cells are more prone to accumulate mutations $(140,144)$. Although prostate stem cells have thus far not been purified in vitro, based on their previous experience, Wang et al (145) retrieved stem cell-like cells from PCa tissues in 2014. At present, PCa stem cells and prostate basal stem cells express a number of similar markers, including CD44, integrin $\alpha 2 \beta 1$ and CD133, which can be used to identify and isolate stem cell populations. Clinically, prostate stem cell surface markers, including prostate stem cell antigen, can be used to assist in the diagnosis of PCa or metastatic tumors of the prostate $(141,142,146)$. Recent evidence has demonstrated that prostate cancer stem-like cells (PCSLCs) serve a critical role in stimulating CRPC evolution and resistance to abiraterone and enzalutamide (147). For CRPC, the drug control of PCa 
stem cells may be a novel targeted therapy direction for future PCa treatments. A precautionary PCa vaccine can also be developed based on characteristics of $\mathrm{PCa}$ stem cells to prevent the progression of human $\mathrm{PCa}$.

\section{Conclusion}

Currently, PCa, particularly advanced and metastatic, has been a continuous burden on the healthcare system; therefore, the clinical research on CRPC has become a hot spot. Multiple mechanisms underlying the resistance to AR targeted therapies have been identified, including AR overexpression with or without amplification, AR mutations, AR-Vs, intratumoral DHT synthesis, GR overexpression, defects of DDR genes and loss of AR, with other therapies to be discovered. In addition to the aforementioned underlying mechanism, including the studies of PSMA, which contains high expression in androgen resistance prostate cells and has been demonstrated to promote the proliferation, invasion and apoptosis of PCa cells (148); additionally, the p100/p52 pathway, one of the NF- $\kappa \mathrm{B}$ pathways, the process of p100 to p52 in $\mathrm{PCa}$ via molecules, including B-cell activating factor, CD40 ligand and STAT3, leads to significant hyperplasia and induces the growth of castration-resistant cells (149). The majority of those advancements in the mechanism understanding of CRPC have provided numerous potential biological targets for the CRPC treatment, including AR antagonist abiraterone and enzalutamide, AR-NTD antagonist EPI-002, PARP inhibitor olaparib, $\mathrm{PI} 3 \mathrm{~K} / \mathrm{mTOR}$ inhibitor BEZ235, chemotherapy drugs cabazitaxel and immunotherapy sipuleucel-T, which can improve the OS and disease-free survival of patients with CRPC (47,92,150-152). In addition, the majority of these pharmaceutical agents are undergoing clinical trials and are being approved for the treatment of CRPC by FDA $(6,153)$; however, all of these agents merely slow the progression of disease, and all patients will inevitably deteriorate into an incurable stage. The changes in the AR signaling pathway, multiple genes and signaling pathways are involved in the process of PCa from early androgen dependence to late CRPC (154), and the underlying mechanism remains at a limited understanding. The interconnection of these signaling pathways form a molecular signaling network, inhibiting a target alone or blocking the occurrence and progression of a signaling pathway is not sufficient to prevent CRPC. To conclude, the focus of the study is to identify and control the key genes targeting these pathways, and effectively prevent PCa from CRPC transformation and evolution, which has an important role in adjustment of CRPC therapeutic strategies, discovery of novel drug targets and improvement of the therapeutic effect.

\section{Acknowledgements}

Not applicable.

\section{Funding}

This study was supported by the Guangzhou Municipal Science and Technology Project (Grant no. 1563000448)

\section{Availability of data and materials}

Not applicable.

\section{Authors' contributions}

JXH and HYQ drafted the manuscript; LX and JGG were responsible for the collection of the relevant literature. All authors have read and approved the final manuscript.

\section{Ethics approval and consent to participate}

This article does not contain any studies with human participants performed by any of the authors.

\section{Consent for publication}

Not applicable.

\section{Competing interests}

The authors declare that they have no competing interests.

\section{References}

1. Siegel RL, Miller KD and Jemal A: Cancer statistics, 2016. CA Cancer J Clin 66: 7-30, 2016.

2. Society AC: Cancer facts \& figures 2016. Atlanta: American Cancer Society 2016.

3. Chen W, Zheng R, Baade PD, Zhang S, Zeng H, Bray F, Jemal A, Yu XQ and He J: Cancer statistics in China, 2015. CA Cancer J Clin 66: 115-132, 2016.

4. Taylor BS, SchultzN, Hieronymus H, Gopalan A, Xiao Y, Carver BS, Arora VK, Kaushik P, Cerami E, Reva B, et al: Integrative genomic profiling of human prostate cancer. Cancer Cell 18: 11-22, 2010.

5. Thomas C, Bögemann M, König F, Machtens S, Schostak M, Steuber $\mathrm{T}$ and Heidenreich A: Advanced prostate cancer consensus conference (APCCC) 2015 in St. Gallen. Critical review of the recommendations on diagnosis and therapy of metastatic prostate cancer by a German expert panel. Urologe A 55: 772-782, 2016 (In German).

6. Ozono S and Furuse H: Progress of the treatment for CRPC. Nihon Rinsho 74 (Suppl 3): S615-S618, 2016 (In Japanese).

7. Lian F, Sharma NV, Moran JD and Moreno CS: The biology of castration-resistant prostate cancer. Curr Probl Cancer 39: 17-28, 2015.

8. Maughan BL and Antonarakis ES: Androgen pathway resistance in prostate cancer and therapeutic implications. Expert Opin Pharmacother 16: 1521-1537, 2015.

9. Roy AK, Tyagi RK, Song CS, Lavrovsky Y, Ahn SC, Oh TS and Chatterjee B: Androgen receptor: Structural domains and functional dynamics after ligand-receptor interaction. Ann N Y Acad Sci 949: 44-57, 2001.

10. Gelmann EP: Molecular biology of the androgen receptor. J Clin Oncol 20: 3001-3015, 2002.

11. Andersen RJ, Mawji NR, Wang J, Wang G, Haile S, Myung JK, Watt K, Tam T, Yang YC, Bañuelos CA, et al: Regression of castrate-recurrent prostate cancer by a small-molecule inhibitor of the amino-terminus domain of the androgen receptor. Cancer Cell 17: 535-546, 2010.

12. Darshan MS, Loftus MS, Thadani-Mulero M, Levy BP, Escuin D, Zhou XK, Gjyrezi A, Chanel-Vos C, Shen R, Tagawa ST, et al: Taxane-induced blockade to nuclear accumulation of the androgen receptor predicts clinical responses in metastatic prostate cancer. Cancer Res 71: 6019-6029, 2011.

13. Aggarwal RR, Thomas G, Youngren J, Foye A, Olson S, Paris P, Beer TM, Ryan CJ, Witte O, Evans CP, et al: Androgen receptor (AR) amplification in patients (pts) with metastatic castration resistant prostate cancer (mCRPC) resistant to abiraterone (Abi) and enzalutamide (Enz): Preliminary results from the SU2C/PCF/AACR West Coast prostate cancer dream team (WCDT). J Clin Oncol 33: 5068, 2015.

14. Haapala K, Kuukasjärvi T, Hyytinen E, Rantala I, Helin HJ and Koivisto PA: Androgen receptor amplification is associated with increased cell proliferation in prostate cancer. Hum Pathol 38: 474-478, 2007. 
15. Attard G, Swennenhuis JF, Olmos D, Reid AH, Vickers E, A'Hern R, Levink R, Coumans F, Moreira J, Riisnaes R, et al: Characterization of ERG, AR and PTEN gene status in circulating tumor cells from patients with castration-resistant prostate cancer. Cancer Res 69: 2912-2918, 2009.

16. Bubendorf L, Kononen J, Koivisto P, Schraml P, Moch H, Gasser TC, Willi N, Mihatsch MJ, Sauter G and Kallioniemi OP: Survey of gene amplifications during prostate cancer progression by high-throughout fluorescence in situ hybridization on tissue microarrays. Cancer Res 59: 803-806, 1999.

17. Linja MJ, Savinainen KJ, Saramäki OR, Tammela TL, Vessella RL and Visakorpi T: Amplification and overexpression of androgen receptor gene in hormone-refractory prostate cancer. Cancer Res 61: 3550-3555, 2001.

18. Chen CD, Welsbie DS, Tran C, Baek SH, Chen R, Vessella R, Rosenfeld MG and Sawyers CL: Molecular determinants of resistance to antiandrogen therapy. Nat Med 10: 33-39, 2004.

19. Kim D, Gregory CW, French FS, Smith GJ and Mohler JL: Androgen receptor expression and cellular proliferation during transition from androgen-dependent to recurrent growth after castration in the CWR22 prostate cancer xenograft. Am J Pathol 160: 219-226, 2002.

20. Santer FR, Erb HH and McNeill RV: Therapy escape mechanisms in the malignant prostate. Seminars Cancer Biol 35: 133-144, 2015.

21. Waltering KK, Helenius MA, Sahu B, Manni V, Linja MJ, Jänne OA and Visakorpi T: Increased expression of androgen receptor sensitizes prostate cancer cells to low levels of androgens. Cancer Res 69: 8141-8149, 2009.

22. Koivisto P, Kononen J, Palmberg C, Tammela T, Hyytinen E, Isola J, Trapman J, Cleutjens K, Noordzij A, Visakorpi T and Kallioniemi OP: Androgen receptor gene amplification: A possible molecular mechanism for androgen deprivation therapy failure in prostate cancer. Cancer Res 57: 314-319, 1997.

23. Barbieri CE, Baca SC, Lawrence MS, Demichelis F, Blattner M, Theurillat JP, White TA, Stojanov P, Van Allen E, Stransky N, et al: Exome sequencing identifies recurrent SPOP, FOXA1 and MED12 mutations in prostate cancer. Nat Genet 44: 685-689, 2012.

24. Mayeur GL, Kung WJ, Martinez A, Izumiya C, Chen DJ and Kung HJ: $\mathrm{Ku}$ is a novel transcriptional recycling coactivator of the androgen receptor in prostate cancer cells. J Biol Chem 280: 10827-10833, 2005.

25. Sarkar S, Brautigan DL, Parsons SJ and Larner JM: Androgen receptor degradation by the E3 ligase CHIP modulates mitotic arrest in prostate cancer cells. Oncogene 33: 26-33, 2014

26. Veldscholte J, Ris-Stalpers C, Kuiper GG, Jenster G, Berrevoets C, Claassen E, van Rooij HC, Trapman J, Brinkmann AO and Mulder E: A mutation in the ligand binding domain of the androgen receptor of human $\mathrm{LNCaP}$ cells affects steroid binding characteristics and response to anti-androgens. Biochem Biophys Res Commun 173: 534-540, 1990.

27. Gaddipati JP, McLeod DG, Heidenberg HB, Sesterhenn IA Finger MJ, Moul JW and Srivastava S: Frequent detection of codon 877 mutation in the androgen receptor gene in advanced prostate cancers. Cancer Res 54: 2861-2864, 1994

28. Suzuki H, Sato N, Watabe Y, Masai M, Seino S and Shimazaki J: Androgen receptor gene mutations in human prostate cancer. J Steroid Biochem Mol Biol 46: 759-765, 1993.

29. Suzuki H, Akakura K, Komiya A, Aida S, Akimoto S and Shimazaki J: Codon 877 mutation in the androgen receptor gene in advanced prostate cancer: Relation to antiandrogen withdrawal syndrome. Prostate 29: 153-158, 1996.

30. Steketee K, Timmerman L, Ziel-van der Made AC, Doesburg P, Brinkmann $\mathrm{AO}$ and Trapman J: Broadened ligand responsiveness of androgen receptor mutants obtained by random amino acid substitution of $\mathrm{H} 874$ and mutation hot spot T877 in prostate cancer. Int J Cancer 100: 309-317, 2002.

31. Balbas MD, Evans MJ, Hosfield DJ, Wongvipat J, Arora VK, Watson PA, Chen Y, Greene GL, Shen Y and Sawyers CL: Overcoming mutation-based resistance to antiandrogens with rational drug design. Elife 2: e00499, 2013.

32. Robinson D, Van Allen EM, Wu YM, Schultz N, Lonigro RJ, Mosquera JM, Montgomery B, Taplin ME, Pritchard CC, Attard G, et al: Integrative clinical genomics of advanced prostate cancer. Cell 161: 1215-1228, 2015.

33. Azad AA, Volik SV, Wyatt AW, Haegert A, Le Bihan S, Bell RH, Anderson SA, McConeghy B, Shukin R, Bazov J, et al: Androgen receptor gene aberrations in circulating cell-free DNA: Biomarkers of therapeutic resistance in castration-resistant prostate cancer. Clin Cancer Res 21: 2315-2324, 2015.
34. Alliance for Clinical Trials in Oncology: Enzalutamide with or without abiraterone and prednisone in treating patients with castration-resistant metastatic prostate cancer. ClinicalTrials. gov Identifier: NCT01949337. https://clinicaltrials.gov/ct2/show/ NCT01949337. Accessed September 24, 2013.

35. Nakazawa M, Antonarakis ES and Luo J: Androgen receptor splice variants in the era of enzalutamide and abiraterone. Horm Cancer 5: 265-273, 2014.

36. Haile S and Sadar MD: Androgen receptor and its splice variants in prostate cancer. Cell Mol Life Sci 68: 3971-3981,2011.

37. Hu R, Dunn TA, Wei S, Isharwal S, Veltri RW, Humphreys E, Han M, Partin AW, Vessella RL, Isaacs WB, et al: Ligand-independent androgen receptor variants derived from splicing of cryptic exons signify hormone-refractory prostate cancer. Cancer Res 69: 16-22, 2009.

38. Guo Z, Yang X, Sun F, Jiang R, Linn DE, Chen H, Chen H, Kong X, Melamed J, Tepper CG, et al: A novel androgen receptor splice variant is up-regulated during prostate cancer progression and promotes androgen depletion-resistant growth. Cancer Res 69: 2305-2313, 2009.

39. Dehm SM, Schmidt LJ, Heemers HV, Vessella RL and Tindall DJ: Splicing of a novel androgen receptor exon generates a constitutively active androgen receptor that mediates prostate cancer therapy resistance. Cancer Res 68: 5469-5477, 2008.

40. Fenner A: Prostate cancer: Unravelling AR splice variant signalling in CPRC. Nat Rev Urol 9: 410, 2012.

41. Ware KE, Garcia-Blanco MA, Armstrong AJ and Dehm SM: Biologic and clinical significance of androgen receptor variants in castration resistant prostate cancer. Endocr Relat Cancer 21: T87-T103, 2014

42. Penel N: Splicing variant of androgen receptors (AR-V7): New paradigms. Bull Cancer 103: 711-713, 2016 (In French).

43. Qu Y, Dai B, Ye D, Kong Y, Chang K, Jia Z, Yang X, Zhang H, Zhu Y and Shi G: Constitutively active AR-V7 plays an essential role in the development and progression of castration-resistant prostate cancer. Sci Rep 5: 7654, 2015.

44. Antonarakis ES, Lu C, Wang H, Luber B, Nakazawa M, Roeser JC, Chen Y, Mohammad TA, Chen Y, Fedor HL, et al: AR-V7 and resistance to enzalutamide and abiraterone in prostate cancer. N Engl J Med 371: 1028-1038, 2014.

45. Zhan Y, Zhang G, Wang X, Qi Y, Bai S, Li D, Ma T, Sartor O, Flemington EK, Zhang $\mathrm{H}$, et al: Interplay between cytoplasmic and nuclear androgen receptor splice variants mediates castration resistance. Mol Cancer Res 15: 59-68, 2017.

46. Yang YC, Mawji N, Wang J and Sadar M: Preclinical evaluation of novel androgen receptor N-terminal domain inhibitor EPI-002 for the treatment of castration-resistant prostate cancer. In: Proceedings of the 105th Annual Meeting of the American Association for Cancer Research, San Diego, CA, 2014. Cancer Res 74 (Suppl 19): Abstract 610, 2014.

47. Ito Y, Banuelos CA and Sadar MD: Combination therapy with EPI-002 and parp inhibitor for castration-resistant prostate cancer. J Urol 197: E1108, 2017.

48. Hermanson O, Glass CK and Rosenfeld MG: Nuclear receptor coregulators: Multiple modes of modification. Trends Endocrinol Metab 13: 55-60, 2002.

49. Culig Z: Androgen receptor coactivators in regulation of growth and differentiation in prostate cancer. J Cell Physiol 231: 270-274, 2016.

50. Wolf IM, Heitzer MD, Grubisha $M$ and DeFranco DB Coactivators and nuclear receptor transactivation. J Cell Biochem 104: 1580-1586, 2008.

51. Massie CE, Adryan B, Barbosa-Morais NL, Lynch AG, Tran MG, Neal DE and Mills IG: New androgen receptor genomic targets show an interaction with the ETS1 transcription factor. EMBO Rep 8: 871-878, 2007.

52. Bennett NC, Gardiner RA, Hooper JD, Johnson DW and Gobe GC: Molecular cell biology of androgen receptor signalling. Int J Biochem Cell Biol 42: 813-827, 2010.

53. Zhang Z, Chang CW, Goh WL, Sung WK and Cheung E: CENTDIST: Discovery of co-associated factors by motif distribution. Nucleic Acids Res 39 (Web Server issue): W391-W399, 2011.

54. Wang Q, Li W, Liu XS, Carroll JS, Jänne OA, Keeton EK, Chinnaiyan AM, Pienta KJ and Brown M: A hierarchical network of transcription factors governs androgen receptor-dependent prostate cancer growth. Mol Cell 27: 380-392, 2007.

55. Tan PY, Chang CW, Chng KR, Wansa KD, Sung WK and Cheung E: Integration of regulatory networks by NKX3-1 promotes androgen-dependent prostate cancer survival. Mol Cell Biol 32: 399-414, 2012. 
56. Heemers HV and Tindall DJ: Androgen receptor (AR) coregulators: A diversity of functions converging on and regulating the AR transcriptional complex. Endocr Rev 28: 778-808, 2007.

57. Ni L, Yang CS, Gioeli D, Frierson H, Toft DO and Paschal BM: FKBP51 promotes assembly of the Hsp90 chaperone complex and regulates androgen receptor signaling in prostate cancer cells. Mol Cell Biol 30: 1243-1253, 2010.

58. Chen S, Sullivan WP, Toft DO and Smith DF: Differential interactions of $\mathrm{p} 23$ and the TPR-containing proteins Hop Cyp40, FKBP52 and FKBP51 with Hsp90 mutants. Cell Stress Chaperones 3: 118-129, 1998.

59. Wissmann M, Yin N, Müller JM, Greschik H, Fodor BD, Jenuwein T, Vogler C, Schneider R, Günther T, Buettner R, et al: Cooperative demethylation by JMJD2C and LSD1 promotes androgen receptor-dependent gene expression. Nat Cell Biol 9: 347-353, 2007.

60. Laschak M, Bechtel M, Spindler KD and Hessenauer A: Inability of NCoR/SMRT to repress androgen receptor transcriptional activity in prostate cancer cell lines. Int J Mol Med 28: 645-651, 2011.

61. Zaret KS and Carroll JS: Pioneer transcription factors: Establishing competence for gene expression. Genes Dev 25: 2227-2241, 2011.

62. Coffey K and Robson CN: Regulation of the androgen receptor by post-translational modifications. J Endocrinol 215: 221-237, 2012.

63. Chen MF, Chen WC, Chang YJ, Wu CF and Wu CT: Role of DNA methyltransferase 1 in hormone-resistant prostate cancer. J Mol Med (Berl) 88: 953-962, 2010.

64. Liu Y, Karaca M, Zhang Z, Gioeli D, Earp HS and Whang YE: Dasatinib inhibits site-specific tyrosine phosphorylation of androgen receptor by Ack1 and Src kinases. Oncogene 29: 3208-3216, 2010.

65. Willder JM, Heng SJ, McCall P, Adams CE, Tannahill C, Fyffe G, Seywright M, Horgan PG, Leung HY, Underwood MA and Edwards J: Androgen receptor phosphorylation at serine 515 by Cdk1 predicts biochemical relapse in prostate cancer patients. Br J Cancer 108: 139-148, 2013.

66. Ha S, Iqbal NJ, Mita P, Ruoff R, Gerald WL, Lepor H, Taneja SS, Lee P, Melamed J, Garabedian MJ and Logan SK: Phosphorylation of the androgen receptor by PIM1 in hormone refractory prostate cancer. Oncogene 32: 3992-4000, 2013.

67. Shu SK, Liu Q, Coppola D and Cheng JQ: Phosphorylation and activation of androgen receptor by Aurora-A. J Biol Chem 285: 33045-33053, 2010.

68. Xia Y, Wang M, Beraldi E, Cong M, Zoubeidi A, Gleave M and Peng L: A novel triazole nucleoside suppresses prostate cancer cell growth by inhibiting heat shock factor 1 and androgen receptor. Anticancer Agents Med Chem 15: 1333-1340, 2015

69. Beltran H, Rickman DS, Park K, Chae SS, Sboner A, MacDonald TY, Wang Y, Sheikh KL, Terry S, Tagawa ST, et al: Molecular characterization of neuroendocrine prostate cancer and identification of new drug targets. Cancer Discov 1: 487-495, 2011.

70. Massie CE, Lynch A, Ramos-Montoya A, Boren J, Stark R, Fazli L, Warren A, Scott H, Madhu B, Sharma N, et al: The androgen receptor fuels prostate cancer by regulating central metabolism and biosynthesis. EMBO J 30: 2719-2733, 2011.

71. Kumagai J, Hofland J, Erkens-Schulze S, Dits NFJ, Jenster G, Bangma CH, Homma Y, De Jong FH and Van Weerden WM: Intratumoral conversion of adrenal androgens is more important than De Novo intratumoral steroid synthesis in prostate cancer. Eur Urol Suppl 10: 264, 2011.

72. Montgomery RB, Mostaghel EA, Vessella R, Hess DL, Kalhorn TF, Higano CS, True LD and Nelson PS: Maintenance of intratumoral androgens in metastatic prostate cancer: A mechanism for castration-resistant tumor growth. Cancer Res 68 4447-4454, 2008.

73. Yin L and Hu Q: CYP17 inhibitors-abiraterone, C17,20-lyase inhibitors and multi-targeting agents. Nat Rev Urol 11: 32-42, 2014.

74. Knuuttila M, Yatkin E, Kallio J, Savolainen S, Laajala TD, Aittokallio T, Oksala R, Häkkinen M, Keski-Rahkonen P, Auriola $\mathrm{S}$, et al: Castration induces up-regulation of intratumoral androgen biosynthesis and androgen receptor expression in an orthotopic VCaP human prostate cancer xenograft model. Am J Pathol 184: 2163-2173, 2014.

75. Tamae D, Mostaghel E, Montgomery B, Nelson PS, Balk SP, Kantoff PW, Taplin ME and Penning TM: The DHEA-sulfate depot following P450c17 inhibition supports the case for AKR1C3 inhibition in high risk localized and advanced castration resistant prostate cancer. Chem Biol Interact 234: 332-338, 2015.
76. Ryan CJ, Smith MR, de Bono JS, Molina A, Logothetis CJ, de Souza P, Fizazi K, Mainwaring P, Piulats JM, Ng S, et al: Abiraterone in metastatic prostate cancer without previous chemotherapy. N Engl J Med 368: 138-148, 2013.

77. Beer TM, Armstrong AJ, Rathkopf DE, Loriot Y, Sternberg CN, Higano CS, Iversen P, Bhattacharya S, Carles J, Chowdhury S, et al: Enzalutamide in metastatic prostate cancer before chemotherapy. N Engl J Med 371: 424-433, 2014.

78. Chandrasekar T, Yang JC, Gao AC and Evans CP: Targeting molecular resistance in castration-resistant prostate cancer. BMC Med 13: 206, 2015.

79. Wang BH: Molecular mechanisms of gene regulation mediated by nuclear receptor superfamily. Sheng Li Ke Xue Jin Zhan 34: 369-372, 2003 (In Chinese).

80. Laudet V, Hänni C, Coll J, Catzeflis F and Stéhelin D: Evolution of the nuclear receptor gene superfamily. EMBO J 11: 1003-1013, 1992.

81. Szmulewitz RZ, Chung E, Al-Ahmadie H, Daniel S, Kocherginsky M, Razmaria A, Zagaja GP, Brendler CB, Stadler WM and Conzen SD: Serum/glucocorticoid-regulated kinase 1 expression in primary human prostate cancers. Prostate 72: 157-164, 2012.

82. Sahu B, Laakso M, Pihlajamaa P, Ovaska K, Sinielnikov I, Hautaniemi S and Jänne OA: FoxA1 specifies unique androgen and glucocorticoid receptor binding events in prostate cancer cells. Cancer Res 73: 1570-1580, 2013.

83. Arora VK, Schenkein E, Murali R, Subudhi SK, Wongvipat J, Balbas MD, Shah N, Cai L, Efstathiou E, Logothetis C, et al: Glucocorticoid receptor confers resistance to antiandrogens by bypassing androgen receptor blockade. Cell 155: 1309-1322, 2013.

84. Montgomery B, Cheng HH, Drechsler J and Mostaghel EA: Glucocorticoids and prostate cancer treatment: Friend or foe? Asian J Androl 16: 354-358, 2014.

85. Montgomery B, Kheoh T, Molina A, Li J, Bellmunt J, Tran N, Loriot Y, Efstathiou E, Ryan CJ, Scher HI and de Bono JS: Impact of baseline corticosteroids on survival and steroid androgens in metastatic castration-resistant prostate cancer: Exploratory analysis from COU-AA-301. Eur Urol 67: 866-873, 2015.

86. Song C, Kim Y, Min GE and Ahn H: Dihydrotestosterone enhances castration-resistant prostate cancer cell proliferation through STAT5 activation via glucocorticoid receptor pathway. Prostate 74: 1240-1248, 2014.

87. Lorente D, Omlin A, Ferraldeschi R, Pezaro C, Perez R, Mateo J, Altavilla A, Zafeirou Z, Tunariu N, Parker C, et al: Tumour responses following a steroid switch from prednisone to dexamethasone in castration-resistant prostate cancer patients progressing on abiraterone. Br J Cancer 111: 2248-2253, 2014.

88. Chen R, Yu Y and Dong X: Progesterone receptor in the prostate: A potential suppressor for benign prostatic hyperplasia and prostate cancer. J Steroid Biochem Mol Biol 166: 91-96, 2017

89. Grindstad T, Andersen S, Al-Saad S, Donnem T, Kiselev Y, Nordahl Melbø-Jørgensen C, Skjefstad K, Busund LT, Bremnes RM and Richardsen E: High progesterone receptor expression in prostate cancer is associated with clinical failure. PloS One 10: e0116691, 2015.

90. Morgensztern D and McLeod HL: PI3K/Akt/mTOR pathway as a target for cancer therapy. Anticancer Drugs 16: 797-803, 2005.

91. Statz CM, Patterson SE and Mockus SM: mTOR inhibitors in castration-resistant prostate cancer: A systematic review. Target Oncol 12: 47-59, 2017.

92. Kato M, Banuelos CA, Imamura Y, Leung JK, Caley DP, Wang J, Mawji NR and Sadar MD: Cotargeting androgen receptor splice variants and mTOR signaling pathway for the treatment of castration-resistant prostate cancer. Clin Cancer Res 22: 2744-2754, 2016.

93. McMenamin ME, Soung P, Perera S, Kaplan I, Loda M and Sellers WR: Loss of PTEN expression in paraffin-embedded primary prostate cancer correlates with high Gleason score and advanced stage. Cancer Res 59: 4291-4296, 1999.

94. Zhang W, Zhu J, Efferson CL, Ware C, Tammam J, Angagaw M, Laskey J, Bettano KA, Kasibhatla S, Reilly JF, et al: Inhibition of tumor growth progression by antiandrogens and mTOR inhibitor in a Pten-deficient mouse model of prostate cancer. Cancer Res 69: 7466-7472, 2009.

95. Park SI, Shah AN, Zhang J and Gallick GE: Regulation of angiogenesis and vascular permeability by Src family kinases: Opportunities for therapeutic treatment of solid tumors. Expert Opin Ther Targets 11: 1207-1217, 2007. 
96. Araujo JC, Trudel GC, Saad F, Armstrong AJ, Yu EY, Bellmunt J, Wilding G, McCaffrey J, Serrano SV, Matveev VB, et al: Docetaxel and dasatinib or placebo in men with metastatic castration-resistant prostate cancer (READY): A randomised, double-blind phase 3 trial. Lancet Oncol 14: 1307-1316, 2013.

97. Yang JC, Bai L, Yap S, Gao AC, Kung HJ and Evans CP: Effect of the specific Src family kinase inhibitor saracatinib on osteolytic lesions using the PC-3 bone model. Mol Cancer Ther 9: 1629-1637, 2010.

98. Bettedi L and Foukas LC: Growth factor, energy and nutrient sensing signalling pathways in metabolic ageing. Biogerontology 18: 913-929, 2017.

99. Neto AS, Tobias-Machado M, Wroclawski ML, Fonseca FL, Pompeo AC and Del Giglio A: Molecular oncogenesis of prostate adenocarcinoma: Role of the human epidermal growth factor receptor 2 (HER-2/neu). Tumori 96: 645-649, 2010.

100. Wen Y, Hu MC, Makino K, Spohn B, Bartholomeusz G, Yan DH and Hung MC: HER-2/neu promotes androgen-independent survival and growth of prostate cancer cells through the Akt pathway. Cancer Res 60: 6841-6845, 2000.

101. Smith DC, Smith MR, Sweeney C, Elfiky AA, Logothetis C, Corn PG, Vogelzang NJ, Small EJ, Harzstark AL, Gordon MS, et al: Cabozantinib in patients with advanced prostate cancer: Results of a phase II randomized discontinuation trial. J Clin Oncol 31: 412-419, 2013.

102. Cannistraci A, Di Pace AL, De Maria R and Bonci D: MicroRNA as new tools for prostate cancer risk assessment and therapeutic intervention: Results from clinical data set and patients' samples. Biomed Res Int 2014: 146170, 2014

103. Kojima S, Goto Y and Naya Y: The roles of microRNAs in the progression of castration-resistant prostate cancer. J Hum Genet 62: 25-31, 2017.

104. Cannistraci A, Di Pace AL, Di Pace AL, De Maria R and Bonci D: MicroRNA as new tools for prostate cancer risk assessment and therapeutic intervention: Results from clinical data set and patients' samples. Biomed Res Int 2014: 146170, 2014

105. Schaefer A, Jung M, Mollenkopf HJ, Wagner I, Stephan C Jentzmik F, Miller K, Lein M, Kristiansen G and Jung K Diagnostic and prognostic implications of microRNA profiling in prostate carcinoma. Int J Cancer 126: 1166-1176, 2010.

106. Jalava SE, Urbanucci A, Latonen L, Waltering KK, Sahu B, Jänne OA, Seppälä J, Lähdesmäki H, Tammela TL and Visakorpi T: Androgen-regulated miR-32 targets BTG2 and is overexpressed in castration-resistant prostate cancer. Oncogene 31: 4460-4471, 2012.

107. Takeshita F, Patrawala L, Osaki M, Takahashi RU, Yamamoto Y, Kosaka N, Kawamata M, Kelnar K, Bader AG, Brown D and Ochiya T: Systemic delivery of synthetic microRNA-16 inhibits the growth of metastatic prostate tumors via downregulation of multiple cell-cycle genes. Mol Ther 18: 181-187, 2010.

108. Kashat M, Azzouz L, Sarkar SH, Kong D, Li Y and Sarkar FH Inactivation of AR and Notch-1 signaling by miR-34a attenuates prostate cancer aggressiveness. Am J Transl Res 4: 432-442, 2012.

109. Majid S, Dar AA, Saini S, Shahryari V, Arora S, Zaman MS, Chang I, Yamamura S, Tanaka Y, Chiyomaru T, et al: miRNA-34b inhibits prostate cancer through demethylation, active chromatin modifications, and AKT pathways. Clin Cancer Res 19: 73-84, 2013.

110. Barron N, Keenan J, Gammell P, Martinez VG, Freeman A, Masters JR and Clynes M: Biochemical relapse following radical prostatectomy and miR-200a levels in prostate cancer. Prostate 72: 1193-1199, 2012.

111. Varambally S, Cao Q, Mani RS, Shankar S, Wang X, Ateeq B, Laxman B, Cao X, Jing X, Ramnarayanan K, et al: Genomic loss of microRNA-101 leads to overexpression of histone methyltransferase EZH2 in cancer. Science 322: 1695-1699, 2008.

112. Mortensen MM, Høyer S, Orntoft TF, Sørensen KD, Dyrskjøt L and Borre M: High miR-449b expression in prostate cancer is associated with biochemical recurrence after radical prostatectomy. BMC Cancer 14: 859, 2014

113. Casanova-Salas I, Rubio-Briones J, Calatrava A, Mancarella C, Masiá E, Casanova J, Fernández-Serra A, Rubio L, Ramírez-Backhaus M, Armiñán A, et al: Identification of miR-187 and miR-182 as biomarkers of early diagnosis and prognosis in patients with prostate cancer treated with radical prostatectomy. J Urol 192: 252-259, 2014.
114. Nam RK, Benatar T, Wallis CJ, Amemiya Y, Yang W, Garbens A, Naeim M, Sherman C, Sugar L and Seth A: MiR-301a regulates E-cadherin expression and is predictive of prostate cancer recurrence. Prostate 76: 869-884, 2016.

115. Bell EH, Kirste S, Fleming JL, Stegmaier P, Drendel V, Mo X, Ling S, Fabian D, Manring I, Jilg CA, et al: A novel miRNA-based predictive model for biochemical failure following post-prostatectomy salvage radiation therapy. PloS One 10: e0118745, 2015.

116. Gallagher DJ, Gaudet MM, Pal P, Kirchhoff T, Balistreri L, Vora K, Bhatia J, Stadler Z, Fine SW, Reuter V, et al: Germline BRCA mutations denote a clinicopathologic subset of prostate cancer. Clin Cancer Res 16: 2115-2121, 2010.

117. Beltran H, Yelensky R, Frampton GM, Park K, Downing SR, MacDonald TY, Jarosz M, Lipson D, Tagawa ST, Nanus DM, et al: Targeted next-generation sequencing of advanced prostate cancer identifies potential therapeutic targets and disease heterogeneity. Eur Urol 63: 920-926, 2013.

118. Castro E, Goh C, Olmos D, Saunders E, Leongamornlert D, Tymrakiewicz M, Mahmud N, Dadaev T, Govindasami K, Guy M, et al: Germline BRCA mutations are associated with higher risk of nodal involvement, distant metastasis, and poor survival outcomes in prostate cancer. J Clin Oncol 31: 1748-1757, 2013.

119. Brenner JC, Ateeq B, Li Y, Yocum AK, Cao Q, Asangani IA, Patel S, Wang X, Liang H, Yu J, et al: Mechanistic rationale for inhibition of poly(ADP-ribose) polymerase in ETS gene fusion-positive prostate cancer. Cancer Cell 19: 664-678, 2011.

120. Mateo J, Carreira S, Sandhu S, Miranda S, Mossop H, Perez-Lopez R, Nava Rodrigues D, Robinson D, Omlin A, Tunariu N, et al: DNA-repair defects and olaparib in metastatic prostate cancer. N Engl J Med 373: 1697-1708, 2015.

121. Polkinghorn WR, Parker JS, Lee MX, Kass EM, Spratt DE, Iaquinta PJ, Arora VK, Yen WF, Cai L, Zheng D, et al: Androgen receptor signaling regulates DNA repair in prostate cancers. Cancer Discov 3: 1245-1253, 2013.

122. Goodwin JF, Schiewer MJ, Dean JL, Schrecengost RS, de Leeuw R, Han S, Ma T, Den RB, Dicker AP, Feng FY and Knudsen KE: A hormone-DNA repair circuit governs the response to genotoxic insult. Cancer Discov 3: 1254-1271, 2013.

123. Li L, Chang W, Yang G, Ren C, Park S, Karantanos T, Karanika S, Wang J, Yin J, Shah PK, et al: Targeting poly(ADP-ribose) polymerase and the c-Myb-regulated DNA damage response pathway in castration-resistant prostate cancer. Sci Signal 7: ra47, 2014.

124. Farrow JM, Yang JC and Evans CP: Autophagy as a modulator and target in prostate cancer. Nat Rev Urol 11: 508-516, 2014

125. Galluzzi L, Pietrocola F, Bravo-San Pedro JM, Amaravadi RK, Baehrecke EH, Cecconi F, Codogno P, Debnath J, Gewirtz DA, Karantza V, et al: Autophagy in malignant transformation and cancer progression. EMBO J 34: 856-880, 2015

126. Jiang X, Zhong W, Huang H, He H, Jiang F, Chen Y, Yue F, Zou J, Li X, He Y, et al: Autophagy defects suggested by low levels of autophagy activator MAP1S and high levels of autophagy inhibitor LRPPRC predict poor prognosis of prostate cancer patients. Mol Carcinog 54: 1194-1204, 2015.

127. Jiang $X, \mathrm{Li} X$, Huang $\mathrm{H}$, Jiang $\mathrm{F}$, Lin $\mathrm{Z}, \mathrm{He} \mathrm{H}$, Chen $\mathrm{Y}$, Yue F, Zou J, He Y, et al: Elevated levels of mitochondrion-associated autophagy inhibitor LRPPRC are associated with poor prognosis in patients with prostate cancer. Cancer 120: 1228-1236, 2014.

128. Mathew R, Karantza-Wadsworth V and White E: Role of autophagy in cancer. Nat Rev Cancer 7: 961-967, 2007.

129. Hönscheid P, Datta K and Muders MH: Autophagy: Detection, regulation and its role in cancer and therapy response. Int $\mathrm{J}$ Radiat Biol 90: 628-635, 2014.

130.Ziparo E, Petrungaro S, Marini ES, Starace D, Conti S, Facchiano A, Filippini A and Giampietri C: Autophagy in prostate cancer and androgen suppression therapy. Int J Mol Sci 14: 12090-12106, 2013.

131. Bennett HL, Stockley J, Fleming JT, Mandal R, O'Prey J, Ryan KM, Robson CN and Leung HY: Does androgen-ablation therapy (AAT) associated autophagy have a pro-survival effect in LNCaP human prostate cancer cells? BJU Int 111: 672-682, 2013.

132. Li M, Jiang X, Liu D, Na Y, Gao GF and Xi Z: Autophagy protects LNCaP cells under androgen deprivation conditions. Autophagy 4: 54-60, 2008. 
133. Xu Y, Chen SY, Ross KN and Balk SP: Androgens induce prostate cancer cell proliferation through mammalian target of rapamycin activation and post-transcriptional increases in cyclin D proteins. Cancer Res 66: 7783-7792, 2006.

134. Stambolic V, MacPherson D, Sas D, Lin Y, Snow B, Jang Y, Benchimol S and Mak TW: Regulation of PTEN transcription by p53. Mol Cell 8: 317-325, 2001.

135. Colquhoun AJ, Venier NA, Vandersluis AD, Besla R, Sugar LM, Kiss A, Fleshner NE, Pollak M, Klotz LH and Venkateswaran V: Metformin enhances the antiproliferative and apoptotic effect of bicalutamide in prostate cancer. Prostate Cancer Prostatic Dis 15: 346-352, 2012.

136. Notte A, Ninane N, Arnould T and Michiels C: Hypoxia counteracts taxol-induced apoptosis in MDA-MB-231 breast cancer cells: Role of autophagy and JNK activation. Cell Death Dis 4: e638, 2013.

137. Li Y, Luo P, Wang J, Dai J, Yang X, Wu H, Yang B and He Q: Autophagy blockade sensitizes the anticancer activity of CA-4 via JNK-Bcl-2 pathway. Toxicol Appl Pharmacol 274: 319-327, 2014.

138. Reya T, Morrison SJ, Clarke MF and Weissman IL: Stem cells, cancer, and cancer stem cells. Nature 414: 105-111, 2001.

139. Maitland NJ, Frame FM, Polson ES, Lewis JL and Collins AT: Prostate cancer stem cells: Do they have a basal or luminal phenotype? Horm Cancer 2: 47-61, 2011.

140. Rizzo S, Attard G and Hudson DL: Prostate epithelial stem cells. Cell Prolif 38: 363-374, 2005.

141. Richardson GD, Robson CN, Lang SH, Neal DE, Maitland NJ and Collins AT: CD133, a novel marker for human prostatic epithelial stem cells. J Cell Sci 117: 3539-3545, 2004.

142. Collins AT, Berry PA, Hyde C, Stower MJ and Maitland NJ: Prospective identification of tumorigenic prostate cancer stem cells. Cancer Res 65: 10946-10951, 2005.

143. Maitland NJ and Collins A: A tumour stem cell hypothesis for the origins of prostate cancer. BJU Int 96: 1219-1223, 2005.

144. Nicolis SK: Cancer stem cells and 'stemness' genes in neuro-oncology. Neurobiol Dis 25: 217-229, 2007.

145. Wang S, Huang S, Zhao X, Zhang Q, Wu M, Sun F, Han G and Wu D: Enrichment of prostate cancer stem cells from primary prostate cancer cultures of biopsy samples. Int J Clin Exp Pathol 7: 184-193, 2013.

146. Tárnok A, Ulrich H and Bocsi J: Phenotypes of stem cells from diverse origin. Cytometry A 77: 6-10, 2010.
147. Ojo D,Lin X, Wong N,Gu Y and Tang D: Prostate cancer stem-like cells contribute to the development of castration-resistant prostate cancer. Cancers (Basel) 7: 2290-2308, 2015.

148. Guo Z, Huang H, Zeng L, Du T, Xu K, Lin T, Jiang C, Dong W, Cao Y, Chen J, et al: Lentivirus-mediated RNAi knockdown of prostate-specific membrane antigen suppresses growth, reduces migration ability and the invasiveness of prostate cancer cells. Med Oncol 28: 878-887, 2011

149. Nadiminty N, Lou W, Lee SO, Lin X, Trump DL and Gao AC: Stat3 activation of NF-(kappa)B p100 processing involves CBP/p300-mediated acetylation. Proc Natl Acad Sci USA 103 7264-7269, 2006.

150. Scher HI, Fizazi K, Saad F, Taplin ME, Sternberg CN, Miller K, de Wit R, Mulders P, Chi KN, Shore ND, et al: Increased survival with enzalutamide in prostate cancer after chemotherapy. N Engl J Med 367: 1187-1197, 2012.

151. Cindolo L, Natoli C, De Nunzio C, De Tursi M, Valeriani M, Giacinti S, Micali S, Rizzo M, Bianchi G, Martorana E, et al: Abiraterone acetate for treatment of metastatic castration-resistant prostate cancer in chemotherapy-naive patients: An Italian analysis of patients' satisfaction. Clin Genitourin Cancer 15: 520-525, 2017

152. Kantoff PW, Higano CS, Shore ND, Berger ER, Small EJ, Penson DF, Redfern CH, Ferrari AC, Dreicer R, Sims RB, et al: Sipuleucel-T immunotherapy for castration-resistant prostate cancer. N Engl J Med 363: 411-422, 2010.

153. Inamoto $\mathrm{T}$ and Azuma $\mathrm{H}$ : Overview of the ongoing clinical trials for new treatments for castrate-resistant prostate cancer (CRPC). Nihon Rinsho 74 (Suppl 3): S653-S659, 2016 (In Japanese).

154. Penning TM: Mechanisms of drug resistance that target the androgen axis in castration resistant prostate cancer (CRPC). J Steroid Biochem Mol Biol 153: 105-113, 2015.

This work is licensed under a Creative Commons Attribution-NonCommercial-NoDerivatives 4.0 International (CC BY-NC-ND 4.0) License. 